\title{
Cost Optimal Design of a Single-Phase Dry Power Transformer
}

\author{
Raju Basak ${ }^{1}$, Arabinda Das $^{2}$, Amarnath Sanyal $^{3}$ \\ ${ }^{1,2}$ Electrical Engineering Department, Jadavpur University, Kolkata -700032, \\ West Bengal, India \\ ${ }^{3}$ Calcutta Institute of Engineering and Management, Kolkata -700040, West Bengal, India \\ email: basakraju149@gmail.com
}

\begin{abstract}
The Dry type transformers are preferred to their oil-immersed counterparts for various reasons, particularly because their operation is hazardless. The application of dry transformers was limited to small ratings in the earlier days. But now these are being used for considerably higher ratings. Therefore, their cost-optimal design has gained importance. This paper deals with the design procedure for achieving cost optimal design of a dry type single-phase power transformer of small rating, subject to usual design constraints on efficiency and voltage regulation. The selling cost for the transformer has been taken as the objective function. Only two key variables have been chosen, the turns/volt and the height: width ratio of window, which affects the cost function to high degrees. Other variables have been chosen on the basis of designers' experience. Copper has been used as conductor material and CRGOS as core material to achieve higher efficiency, lower running cost and compact design. The electrical and magnetic loadings have been kept at their maximum values without violating the design constraints. The optimal solution has been obtained by the method of exhaustive search using nested loops.
\end{abstract}

Keywords: transformer, optimal design, design variables, design constraints, exhaustive search

\section{Introduction}

Dry type transformers have recently become much popular [1]. In the earlier days these were used for small rating power transformers only. But now-a-days these are also finding application as distribution transformers and they are being used for relatively much higher rating. In oil-filled transformers, the maintenance requirement is relatively more. A conservator is to be provided to take care of expansion and contraction of oil with load cycles. The ingress of moisture is to be counteracted by providing breather connected to the conservator. It has to be filled up with fused silica gel which need be checked at regular intervals. If oil-filled transformers are not properly maintained, there are chances of dielectric failure due to contamination of oil. In extreme cases the tank may burst and hot oil thrown off around the tank thus endangering nearby people. Moreover, the presence of oil is always associated with some amount of leakage which makes the near-by places dirty. For all these reasons, dry transformers are getting preference over the oil-filled type [2]-[4].

Oil is used as filler for two reasons- better cooling and enhancing the dielectric strength of oil. Cooling conditions are inferior in case of a dry transformer as the cooling medium is air. Therefore dry transformers are to be designed for lower current density. The cost of conductor, and as such the over-all cost, for the same rating, becomes a little higher in comparison to oilfilled transformers. But in consideration of compactness of the design, absence of oil-hazards and neatness of the environment makes dry transformers quite attractive. Dry type resin-cast transformers are still more expensive but their performance is highly satisfactory [5],[6].

\section{Cost Optimality and Quality Design}

As dry transformers are gradually replacing their oil-filled counterparts, their costoptimal design is of great importance in the present context. In this paper, the cost of production (selling cost) has been taken as the objective function. However, the annual running losses or life-time losses may also be included in the cost function for dual optimization from the point of view of the customer and the manufacturer [7]. 
The core construction has been used as it is more economic than the shell type. Copper has been used as conductor for compactness of design. High price nomex-insulated conductors have been recommended as they can withstand higher temperature. Cold rolled grain-oriented silicon steel has been recommended as core material. The choice of materials has been made with a view to achieve higher efficiency and reduce the running losses [6],[7].

\section{The Optimizing Techniques}

A design problem does not have a unique solution. Generally there are many feasible solutions. Optimization is the way to find out the best possible solution out of them. Several techniques have evolved through centuries to deal with optimal solution. Some of them are traditional based on mathematical formulation and some of them are non-traditional based on soft-computing techniques. The chief contribution is from the mathematicians. The engineers and the technicians have merely applied them to real world industrial problems and designs. Searching for the optimal solution requires much iteration. It is difficult to expedite the same through long-hand calculations using a calculator. For reaching optimal solution recourse must be made to a digital computer as it can perform calculations at an extremely high rate and it has got large amount of memory. De facto, it is the advent of computer which has revolutionized the field of optimization [8]-[10].

The process of optimization starts by choosing the design variables for a particular problem and listing the design constraints. The key variables are to be identified and their bounds defined. Then the objective function (or the cost function) is to be formulated. Then we are to search for optimality (maximality or minimality as the case may be) using an appropriate mathematical technique.

In this section, it is explained the results of research and at the same time is given the comprehensive discussion. Results can be presented in figures, graphs, tables and others that make the reader understand easily [11],[12]. The discussion can be made in several subchapters.

\subsection{Exhaustive search method}

Using nested loops is the simplest of all search methods. The optimum of a function is bracketed by calculating the function values at a number of equally spaced points. Usually the search begin from a lower bound on the variable and the consecutive function values are compared at a time based on the assumption of unimodality of the function. Based on the outcome of comparison, the search is either terminated or continued by replacing one from the above points with a new point. Figure 1 shows the method graphically for a univaraiate objective function.

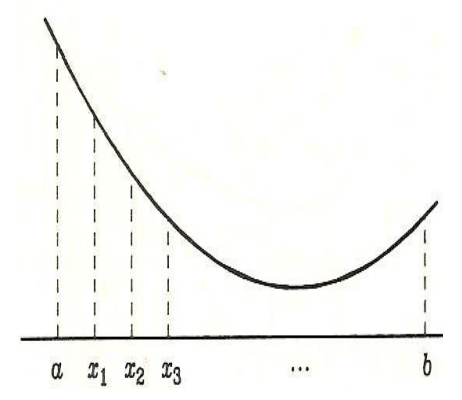

Figure 1. Exhaustive search plane

\subsection{Multivariable search}

Single variable optimization is simple. But unfortunately, the design optimization problems are multi-variable and constrained. Obviously, the problems are complicated by nature. These are addressed by methods like:

i) Repeated unidirectional search (in each direction defined by the variables)

ii) Direct search methods or

iii) Gradient-based methods.

IJEEI Vol. 3, No. 4, December 2015: $261-266$ 
The Direct search or gradient methods are mathematically sophisticated. On the contrary, the method of exhaustive search is much simpler. It is a bracketing method, normally used for single variable but it can be extended to multiple variables. Though the no of iterations is more in this method, the solution does not get stuck to local minima. If the step lengths are not too large, then it is almost sure to reach the optimal solution. Therefore, we have chosen the method of exhaustive search [12]-[14].

There are also powerful methods for design optimization using soft-computing techniques [15],[16] e.g., genetic algorithm, simulated annealing etc.

\section{Design Variables and Constraints}

There are several design variables for the design of a power transformer. Some of them affect the objective function to a large extent. These are called key variables. Other variables have rather less influence on the objective function. The optimal solution is sought by varying the key variables only. Other variables are kept constant at their usual values.

The variables may be continuous or integer. For example, the no of turns of the primary and the secondary windings in each limb must be an integer. However if the number is large, they can be treated as continuous variables. The following key variables have been identified:

$\mathrm{K}=$ emf constant (in $\mathrm{E}_{\mathrm{t}}=\mathrm{K} \sqrt{ } \mathrm{S}$, where $\mathrm{E}_{\mathrm{t}}=$ emf/turn, $\mathrm{S}=$ rating in $\mathrm{KVA}$ )

$\mathrm{R}_{\mathrm{w}}=\mathrm{H}_{\mathrm{w}} / \mathrm{W}_{\mathrm{w}}=$ Height: Width ratio of the transformer;

$\delta=$ current density in the conductor in $\mathrm{A} / \mathrm{mm}^{2} ; B_{m}=$ Maximum flux-density, Tesla

It has been found that the cost of production continuously reduces with increasing $B_{m}$ and $\delta$. So they are not candidate variables for optimization. They are fixed at their maximum values for which the constraints are not violated. Appropriate values for other variables have been chosen by consulting design data-books and text-books.

In addition, there are some decision-variables e.g.

(a) Core or shell construction: Core construction has been used for greater economy

(b) Conductor material- copper or aluminium: Higher efficiency is achievable with copper and the design is compact. Therefore, copper has been used as conductor materials.

(c) Core material- CRNOS or CRGOS: CRGOS has been used to reduce the iron loss to minimum and achieve greater efficiency.

(d) Cooling AN or ANAF: Air natural cooling has been used. It is enough for transformers of small ratings. To keep the temperature rise within statutory limits.

Constraints have been imposed on: Maximum \% copper loss $\leq 2.5 \%$; Maximum $\%$ iron loss $\leq 1.0 \%$, with a view to limit the temperature rise; Maximum efficiency at CMR $\geq 96 \%$. Maximum temperature rise of the coil $\leq 75^{\circ} \mathrm{C}$; Voltage regulation $\leq 3 \%$

\section{Algorithm}

The following algorithm has been used to solve the design problem

Step 1: Input specifications of the power transformer: power and voltage ratings.

Step 2: Choose copper as conductor material, CRGOS as core material. Initialize: $\min \leftarrow a$ large number

Step 3: Input user-specified data for design variables: flux density $\left(B_{m}\right)$, current density $(\delta)$, number of core steps $\left(\mathrm{N}_{\mathrm{st}}\right)$ etc.

Step 4: For $\mathrm{i}=0$ to 30 do: $\mathrm{K} \leftarrow 0.5+\mathrm{i} / 100 \quad$ 'Bound: 0.5 to 0.8

Step 5: For $\mathrm{j}=0$ to $20 \mathrm{do}: \mathrm{R}_{\mathrm{w}} \leftarrow 2.5+\mathrm{j} / 20 \quad$ 'Bound 2.5 to 3.5

Step 6: Go to transformer design sub-routine, calculate the objective function, $\mathrm{C}(\mathrm{i}, \mathrm{j})$ and the performance variables.

Step 7: If efficiency < $96 \%$ Go to step 12

Step 8: If voltage regulation $>3 \%$ Go to step 12

Step 9: If temp. Rise of coil $>90^{\circ} \mathrm{C}$ go to step 12

Step 10: if $\mathrm{C}(\mathrm{i}, \mathrm{j})>\min$ go to step 12

Step 11: $\mathrm{K}_{\text {min }} \leftarrow \mathrm{K}(\mathrm{i}) ; \mathrm{R}_{\mathrm{w} \text { min }} \leftarrow \mathrm{R}_{\mathrm{w}}(\mathrm{j}) ; \mathrm{C}_{\min } \leftarrow \mathrm{C}(\mathrm{I}, \mathrm{j})$

Step 12: end for

Step 13: end for

Step 14: Put $\mathrm{K} \leftarrow \mathrm{K}_{\min } ; \mathrm{R}_{\mathrm{w}} \leftarrow \mathrm{R}_{\mathrm{w} \text { min }}$

Step 15: Go to transformer design sub-routine, 
Calculate the objective function, $\mathrm{C}(\mathrm{i})$ and the performance variables.

Step 16: Print out results

Step 17: Stop

Step 18: End

\section{The Design Problem}

Optimal design of a small dry type 1-phase transformer has been taken. Core construction has been preferred as it is more economic.

\subsection{Transformer rating}

$\mathrm{KVA}=5$; frequency $=50 \mathrm{~Hz}$. Power factor = 0.8 lagging; Primary/Secondary voltage: $230 \mathrm{~V} / 115 \mathrm{~V}$

\subsection{Specifications}

Efficiency: efficiency $\geq 0.96$; voltage regulation: $\leq 3 \%$; temp. Rise $\leq 75^{\circ} \mathrm{C}$. CRGOS has been used as core material \& Copper as conductor material. Cruciform core has been used. Cylindrical type coils have been used for both primary and secondary. Flux-density/ current density have been kept at maximum values withoutviolating the constraints. Chosen value of magnetic and electric loading:

The flux-density=1.6 Tesla and current density= $2.5 \mathrm{~A} / \mathrm{mm}^{2}$.

The resistivity of copper at operating temperature has been taken as $0.021 \Omega / \mathrm{m} / \mathrm{mm}^{2}$

Other constants: stacking factor $=0.92$; window space factor $=0.45$

With reference to the table of convergence given below the objective function reduces toits minimum: Rs. $12100 /-$ for: $K=0.65 ; R_{w}=3.1$

With these values of the design variables, we get the following results:

EMF/turn= 1.5541 Volt; No of turns of primary/secondary: $148 / 74$

Core flux $=7.0002 \mathrm{E}-03$ Waber; Net area of iron $=4.3752 \mathrm{E}-03 \mathrm{~m} 2$

Diameter of circumscribing cycle of the core $=8.7439 \mathrm{E}-02 \mathrm{~m}$

Length of the sides in $\mathrm{m}$ : 0.074 / 0.046; Distance between core centers $=0.12787 \mathrm{~m}$

Total width $=0.20187 \mathrm{~m}$; Window height/width, $\mathrm{m}: 0.1415 ; 4.043 \mathrm{E}-02$

Height of yoke/ total height in $\mathrm{m}$ : $6.4265 \mathrm{E}-02 ; 0.2700$

\subsection{Coil design}

Primary and secondary coils are split into two halves in two limbs.

The primary/secondary current, a: $21.739 ; 43.478$

Cylindrical windings are being used for both primary and secondary.

Required cross-section of the primary/secondary windings, $\mathrm{mm}^{2}$ : $8.6957 ; 17.391$

Cross-sections are large for both primary and secondary. So strip conductors are being used.

Chosen dimension of the strip for secondary: $3.4 \mathrm{~mm} \times 5.1 \mathrm{~mm}$

Chosen dimension of the strip for primary: $1.6 \mathrm{~mm} \times 5.4 \mathrm{~mm}$

Actual conductor cross-section of primary and secondary, $\mathrm{mm}^{2}: 8.64 ; 17.34$

Thickness of insulation on the core $=1.5 \mathrm{~mm}$

Gap between LV and HV windings $=5 \mathrm{~mm}$

Inside/Outside radius of secondary, $\mathrm{mm}: 90.439 ; 100.64$

Inside/Outside radius of primary, $\mathrm{mm}$ : 110.66; 121.44

Clearance between adjacent $\mathrm{HV}$ windings $=6.4256 \mathrm{~mm}$

The clearance is adequate for L.V. windings.

\subsection{Performance evaluation}

Resistance of the primary/secondary winding, $\Omega: 0.13031 ; 2.6823 E-02$

Copper loss at rated current $=112.29 \mathrm{~W} ; \%$ copper loss $=2.2458$

The $\%$ leakage reactance $=0.85873, \%$ No Load current $=1.558$.

Voltage regulation at full load and 0.8 lagging p.f. $=2.312$

Iron loss/kg= $1.9632 \mathrm{~W}$

Iron loss at rated voltage $=45.12 \mathrm{~W} ; \%$ iron loss $=0.9024$

Efficiency at rated load and nominal $\mathrm{pf}=0.96214$

Cooling coefficient has been taken as 0.05 (on the higher side as there is no forced cooling.)

IJEEI Vol. 3, No. 4, December 2015: $261-266$ 
Exposed area of the coil $=0.18568 \mathrm{~m}^{2}$; Average temperature rise of coils $=42.48{ }^{\circ} \mathrm{C}$

The constraints on voltage regulation, efficiency and temperature rise have not been violated.

\subsection{Cost analysis}

Weight of iron= $22.984 \mathrm{Kg}$; Cost of iron= Rs. 3677/-

Weight of copper $=7.614343 \mathrm{Kg} . ;$ Cost of copper= Rs. 4378/-

Total cost of iron and copper $=$ Rs. 8056/-

Manufacturing cost allowing $50 \%$ on cost of materials= Rs. $12148 /-$

(The slight difference in cost arises out of integer variables replacing real e.g. no. of turns etc.)

Annual loss on the basis of average $80 \%$ loading $=842.31 \mathrm{~kW}-\mathrm{h}$.

Price of a BOT unit= Rs. 5/-

Annual cost of lost energy = Rs. 4211/-

Table 1 shows the improvement parameters over conventional design. Comparison with a manufacturer's data for the same machine is given in Table 2 .

Table 1. The improvement parameters over conventional design

\begin{tabular}{|c|c|c|c|c|c|c|c|c|}
\hline $\bar{K}$ & $\mathrm{R}_{\mathrm{w}}$ & Cost & $\mathrm{K}$ & $\mathrm{R}_{\mathrm{w}}$ & Cost & $\mathrm{K}$ & $R_{w}$ & Cost \\
\hline 0.60 & 2.50 & 12184 & 0.60 & 2.60 & 12171 & 0.60 & 2.70 & 12161 \\
\hline 0.60 & 2.80 & 12152 & 0.60 & 2.90 & 12145 & 0.60 & 3.00 & 12139 \\
\hline 0.60 & 3.10 & 12135 & 0.60 & 3.20 & 12132 & 0.60 & 3.30 & 12130 \\
\hline 0.60 & 3.40 & 12128 & 0.60 & 3.50 & 12128 & 0.61 & 2.50 & 12166 \\
\hline 0.61 & 2.60 & 12154 & 0.61 & 2.70 & 12145 & 0.61 & 2.80 & 12137 \\
\hline 0.61 & 2.90 & 12131 & 0.61 & 3.00 & 12126 & 0.61 & 3.10 & 12122 \\
\hline 0.61 & 3.20 & 12120 & 0.61 & 3.30 & 12118 & 0.61 & 3.40 & 12118 \\
\hline 0.61 & 3.50 & 12119 & 0.62 & 2.50 & 12151 & 0.62 & 2.60 & 12140 \\
\hline 0.62 & 2.70 & 12132 & 0.62 & 2.80 & 12125 & 0.62 & 2.90 & 12119 \\
\hline 0.62 & 3.00 & 12115 & 0.62 & 3.10 & 12112 & 0.62 & 3.20 & 12111 \\
\hline 0.62 & 3.30 & 12110 & 0.62 & 3.40 & 12111 & 0.62 & 3.50 & 12112 \\
\hline 0.63 & 3.50 & 12139 & 0.63 & 2.60 & 12130 & 0.63 & 2.70 & 12122 \\
\hline 0.63 & 2.80 & 12116 & 0.63 & 2.90 & 12111 & 0.63 & 3.00 & 12108 \\
\hline 0.63 & 3.10 & 12106 & 0.63 & 3.20 & 12105 & 0.63 & 3.30 & 12105 \\
\hline 0.63 & 3.40 & 12106 & 0.63 & 3.50 & 12108 & 0.64 & 2.50 & 12130 \\
\hline 0.64 & 2.60 & 12121 & 0.64 & 2.70 & 12114 & 0.64 & 2.80 & 12109 \\
\hline 0.64 & 2.90 & 12105 & 0.64 & 3.00 & 12103 & 0.64 & 3.10 & 12102 \\
\hline 0.64 & 3.50 & 12107 & 0.65 & 2.50 & 12124 & 0.65 & 2.60 & 12116 \\
\hline 0.65 & 2.70 & 12110 & 0.65 & 2.80 & 12105 & 0.65 & 2.90 & 12102 \\
\hline 0.65 & 3.00 & 12101 & 0.65 & 3.10 & 12100 & 0.65 & 3.20 & 12101 \\
\hline 0.65 & 3.30 & 12102 & 0.65 & 3.40 & 12105 & 0.65 & 3.50 & 12108 \\
\hline 0.66 & 2.50 & 12120 & 0.66 & 2.60 & 12113 & 0.66 & 2.70 & 12108 \\
\hline 0.66 & 2.80 & 12104 & 0.66 & 2.90 & 12102 & 0.66 & 3.00 & 12101 \\
\hline 0.66 & 3.10 & 12101 & 0.66 & 3.20 & 12102 & 0.66 & 3.30 & 12105 \\
\hline 0.66 & 3.40 & 12100 & 0.66 & 3.50 & 12111 & 0.67 & 2.50 & 12119 \\
\hline 0.67 & 2.60 & 12113 & 0.67 & 2.70 & 12109 & 0.67 & 2.80 & 12106 \\
\hline 0.67 & 2.90 & 12104 & 0.67 & 3.00 & 12104 & 0.67 & 3.10 & 12105 \\
\hline 0.67 & 3.20 & 12106 & 0.67 & 3.30 & 12109 & 0.67 & 3.40 & 12113 \\
\hline 0.67 & 3.50 & 12117 & 0.68 & 2.50 & 12121 & 0.68 & 2.60 & 12115 \\
\hline 0.68 & 2.70 & 12112 & 0.68 & 2.80 & 12109 & 0.68 & 2.90 & 12108 \\
\hline 0.68 & 3.00 & 12109 & 0.68 & 3.10 & 12110 & 0.68 & 3.20 & 12113 \\
\hline 0.68 & 3.30 & 12116 & 0.68 & 3.40 & 12120 & 0.68 & 3.50 & 12125 \\
\hline 0.69 & 2.50 & 12124 & 0.69 & 2.60 & 12120 & 0.69 & 2.70 & 12117 \\
\hline 0.69 & 2.80 & 12115 & 0.69 & 2.90 & 12115 & 0.69 & 3.00 & 12116 \\
\hline 0.69 & 3.10 & 12118 & 0.69 & 3.20 & 12121 & 0.69 & 3.30 & 12125 \\
\hline 0.69 & 3.40 & 12130 & 0.69 & 3.50 & 12136 & 0.70 & 2.50 & 12130 \\
\hline 0.70 & 2.60 & 12126 & 0.70 & 2.70 & 12124 & 0.70 & 2.80 & 12123 \\
\hline 0.70 & 2.90 & 12124 & 0.70 & 3.00 & 12126 & 0.70 & 3.10 & 12128 \\
\hline 0.70 & 3.20 & 12132 & 0.70 & 3.30 & 12137 & 0.70 & 3.40 & 12142 \\
\hline 0.70 & 3.50 & 12148 & & & & & & \\
\hline
\end{tabular}

Table 2. Comparison with a manufacturer's data for the same machine

\begin{tabular}{lcc}
\hline \multicolumn{1}{c}{ Item } & Optimal Design & Manufacturers' data \\
\hline Total cost of materials & Rs. 8056/- & Rs. 9285/- \\
\% iron loss & 0.9024 & 0.5824 \\
\% copper loss & 2.2458 & 3.2431 \\
Efficiency at full load, 0.8 lagging p.f. & 0.96214 & 0.9724 \\
\% no load current & 1.558 & 1.3 \\
\% Leakage reactance & 0.85873 & 0.7534 \\
\% Voltage regulation at full load, 0.8 lagging p.f. & 2.312 & 3.61 \\
\hline
\end{tabular}




\section{Conclusion}

The paper has dealt with design optimization of a single phase dry type power transformer. The dry transformers are used where we like to have a compact design and trouble-free operation at low cost of maintenance. These transformers now find application as small and medium-sized transformers where cost is not an impediment. Core constructions are preferred as they are more economic [17],[18]. Best grade materials e.g. CRGOS as core material and refined copper as conductor material are used to achieve higher efficiency and to reduce the running losses. The key variables which affect the cost of production have been identified as the emf constant, $K$ and the window height: width ratio $R_{\mathrm{w}}$. The bounds on the design variables have been found out from the text-books on design. The optimal solution has been found out by the method of exhaustive search using nested loops. The step lengths have been chosen judiciously so as not to skip the optima. A case study has been made on a 5 KVA, $230 / 115 \mathrm{~V}, 50 \mathrm{~Hz}$, 1-phase power transformer. The design details of the optimal machine have been documented. All the specifications have been fulfilled- no constraints have been violated.

If the design is not methodically made, we cannot aspire to reach an optimal solution. A comparison of performance and cost is given in tabular form (Table 2), where manufacturer's data has been compared with the obtained optimal design data. It shows that the cost of the optimal machine is much less and most of the performance indices are better.

\section{References}

[1] R. Basak, A. Das, A. Sensarma, AN. Sanyal. Discrete design Optimization of small open type dry transformers. Bulletin Teknik Elektrodan Informatika. 2012; 1(1): 37-42. ISSN: 2089-3191.

[2] AK. Shawney. A course in electrical machine design. DhanpatRai\& Sons. 2003.

[3] MG. Say. Performance and design of A.C. machines. CBS Publishers \& Distributors. 2005.

[4] I. Dasgupta. Design of Transformers. TMH, New Delhi. 2002.

[5] A. Still. Principles of Transformer Design. John Wiley and Sons Inc. 2007.

[6] MJ. Heathcote. The J \& P Transformer Book $12^{\text {th }}$. Edition- a practical technology of the power transformer. 1998.

[7] A. Khatri, OP. Rahi. Optimal design of transformer: a compressive bibliographical survey. 2012; 1(2): 159-167. ISSN: 2277-1581.

[8] SB. Williams, PA. Abetti, EF. Mangnusson. Application of digital computers to transformer design. AIEE Trans. 1956; 75(III): 728-35.

[9] WA. Shapley, JB. Oldfield. The digital computer applied to the design of large power transformers. Proc. IEE. 1958; 105: 112-25.

[10] SB. Williams, PA. Abetti, HJ. Mason. Complete design of power transformer with a large size digital transformer. AlEE trans. 1959; 77: 1282-91.

[11] OW. Anderson. Optimum design of electrical machines. IEEE Trans. (PAS). 1967; 86: 707-11.

[12] M. Ramamoorty. Computer-aided design of electrical equipment. Affiliated East-West press. 1987.

[13] K. Deb. Optimization for engineering design. PHI. 2010. ISBN 978-81-203-0943-2.

[14] SS. Rao. Engineering optimization- theory and practice. New Age Int. 2013. ISBN978-81-224-2723-3.

[15] AK. Yadav, et al. Optimization of Power Transformer Design using Simulated Annealing Technique. International Journal of Electrical Engineering. 2011; 4(2): 191-198, ISSN 0974-2158.

[16] RA. Jabr. Application of geometric programming to transformer design. IEEE Trans Magnetics. 2005; 41: 4261-4269.

[17] A. Shanmugasundaram, G. Gangadharan, R. Palani. Electrical machine design data book. Wiley eastern Ltd. ISBN 0852268130.

[18] R. Basak, A. Das, AN. Sanyal. Optimal Design of a 3-phase core type Distribution Transformer using Modified Hooke and Jeeves Method. TELKOMNIKA Indonesian Journal of Electrical Engineering. 2014; 12(10): 7114-7122. 